\title{
Pitfalls in the assessment of murine atherosclerosis
}

\author{
S. Catanozi, J.C. Rocha, M. Passarelli, F.C. Chiquito, E.C.R. Quintão and \\ E.R. Nakandakare \\ Laboratório de Lípides (LIM 10), Faculdade de Medicina, Universidade de São Paulo, São Paulo, \\ SP, Brasil
}

Correspondence to: S. Catanozi, Laboratório de Lípides (LIM 10), Faculdade de Medicina, USP, Av. Dr. Arnaldo, 455, Sala 3305, 01246-000 São Paulo, SP, Brasil

Fax:+55-11-3061-7263. E-mail: catanozi@usp.br

This review provides examples of the fact that different procedures for the measurement of atherosclerosis in mice may lead to interpretation of the extent of atherosclerosis having markedly different biological and clinical significance for humans: 1) aortic cholesterol measurement is highly sensitive for the detection of early and advanced atherosclerosis lesions, but misses the identification of the location and complexity of these lesions that are so critical for humans; 2) the histological analysis of the aortic root lesions in simvastatin-treated and control mice reveals similar lesion morphology in spite of the remarkable simvastatin-induced reduction of the aortic cholesteryl ester content; 3) in histological analyses, chemical fixation and inclusion may extract the tissue fat and also shrink and distort tissue structures. Thus, the method may be less sensitive for the detection of slight differences among the experimental groups, unless a more suitable procedure employing physical fixation with histological sample freezing using optimal cutting temperature and liquid nitrogen is employed. Thus, when measuring experimental atherosclerosis in mice, investigators should be aware of several previously unreported pitfalls regarding the extent, location and complexity of the arterial lesion that may not be suitable for extrapolation to human pathology.

Key words: Atherosclerosis; Animal models; Disease models; Aorta; Pathology

Research supported by PRONEX (CNPq \#66.1092/1997-2), FAPESP, and Medical Investigation Laboratory of Hospital das Clínicas (LIM), Faculty of Medical Sciences, University of São Paulo.

Received July 25, 2008. Accepted March 11, 2009

\section{Introduction}

Rabbits, rats, mice, pigeons, pigs, and monkeys are often used in atherosclerosis research, but in some of these species the plasma lipoprotein profile and the pattern of atherosclerosis lesion differ from those of humans. Rats, for example, are not suitable models for atherosclerosis research because they do not develop vascular lesion spontaneously, unless fed an extremely atherogenic diet (1). For these reasons, most of the atherosclerosis studies have been previously restricted to rabbits, pigs and primates. However, handling difficulties, large animals' breeding expenses and the risk of non-human primate extinction have increased the need for the development of murine models of atherosclerosis $(2,3)$. Other parameters that are considered in the choice of a model are breeding time and rate and intensity of lesion development, as well as the facilities needed to perform experiments. These needs have led to the development of genetically modified mice as models for experimental atherosclerosis (4) that include random insertion of new genes, insertion of specific mutations in the loci of the wild-type alleles, and disruption of a specific allele (3). Several genetically modified mice present an altered lipoprotein profile, often similar to that of human dyslipidemias, suitable for investigations of the arterial lesions (5), such as apolipoprotein $\mathrm{E}$ (apoE) or low-density lipoprotein receptor (LDLR) knockouts (KO). Both models are hyperlipidemic; however, the apoE KO animals, even when fed a chow diet, display more severe or complex lesions than LDLR 
KO mice fed a western diet (6-10).

Atherosclerosis can be measured by several methods such as size of the lesions, cell types and biochemical changes that take place at distinct sites of the vascular bed due to exposure to diverse hemodynamic forces. Additionally, precision, cost and technical convenience are important factors that lead to the choice of the procedure used for the histological and chemical methods of atherosclerosis quantification. Since the technical details of each method have been properly described elsewhere (references in the text below), the purpose of the present review was to discuss the adequacy of each histological and chemical procedure regarding the objectives of the experimental design used to produce atherosclerosis.

\section{Analysis of aortic intima (en face)}

Briefly, a longitudinal incision is performed in the inner curvature of the aortic arch through the anterior surface as far as the distal aorta. An identical surgical procedure is carried out in the outer curvature of the aortic arch as far as the subclavian branch. The aorta is then pinned on a blackboard for quantification of the atherosclerotic lesion area, which is commonly represented as a percent of total intimal surface. Due to the fact that it does not consider the lesion thickness, which can be determined either by histological sectioning or by measuring the amount of unesterified and esterified cholesterol, the procedure is limited in the sense that it is a two-dimensional technique for the measurement of atherosclerotic lesions (11-15).

\section{Chemical analysis of atherosclerosis of the aorta}

Atherosclerotic lesion intensity can also be quantitatively determined by measurement of free cholesterol and total cholesterol in the whole aorta. In this case, the adventitia has to be painstakingly and completely dissected and removed from the aorta under a dissecting microscope, but this is a time-consuming and cumbersome procedure. Lipids from the aortic intima and media preparation are then extracted with chloroform-methanol (2:1) using $5 \alpha$-cholestane as an internal standard and total, free and esterified cholesterol concentrations are quantified either by gas-liquid chromatography (16) or by commercially available enzymatic kits. In the latter, the first step is carried out only with cholesterol oxidase for the measurement of unesterified cholesterol, and then cholesteryl ester hydrolase is added for the measurement of total cholesterol, with the esterified component being the difference between the total cholesterol and the unesterified fraction (17-20).

\section{Serial histological analysis of atherosclerosis of the aorta}

Serial histological sectioning is the usual procedure for tissue investigations. In most situations, tissues have to be thinly sectioned using a microtome. Ideal microscopic preparations should contain not only the structural components, but also the molecular and chemical components as well preserved as possible, mirroring the tissue of a living animal. In other words, to avoid autolysis or post-mortem degradation, biological materials are subjected to fixation procedures for the preservation, stabilization and maintenance of the structure of the organs, tissues and their cells (13). Thus, the choice between a chemical and a physical fixation depends on which lesion feature the investigator wishes to demonstrate. Chemical fixation with phosphatebuffered $4 \%$ formaldehyde or $4 \%$ paraformaldehyde and gelatin inclusion to obtain proper arterial stiffness has been extensively used $(21,22)$. However, physical fixation by sample freezing using optimal cutting temperature embedding medium (Tissue-Tek, Sakura Finetek, USA) and liquid nitrogen is indicated to preserve the structural components of the artery and the integrity of the chemical components (23-25). The physical fixation limits the loss of chemical components. Sample sectioning is then carried out at low temperature $\left(-18\right.$ to $\left.-30^{\circ} \mathrm{C}\right)$ with a cryostat.

After the chemical or physical fixation, staining of histological sections for lipid analysis is generally carried out with fat-soluble dyes, such as oil red-O, Sudan IV and Sudan black. Atherosclerosis measurement can then be expressed as the lesion cross-sectional area.

\section{Method choice}

Since there are several methods for the measurement of atherosclerosis, each of them with its peculiarities, we illustrate here their applicability with specific examples.

Depending on the mouse model used, a high-fat diet can elicit blood cholesterol concentrations as high as 1000 $\mathrm{mg} / \mathrm{dL}$, which far exceeds the values observed in the most severe forms of familial hypercholesterolemia in humans. The animal's age during the study period is another important factor to be considered since in old animals fed regular chow, such as apoE KO, atherosclerotic lesions grow in size and develop gradually in complexity (22). Atherosclerotic lesions can be observed grossly even during dissection of the mouse aorta (Figure 1). Very often these experimental situations result in extensive lesion development along the aorta and atherosclerotic lesions are then quite often assessed by en face analysis of the whole aorta $(15,22)$. Nevertheless, it has been shown that the sensitiv- 
ity of this technique is low both for groups fed on a regular mouse chow and for young animals, and may not accurately measure the degree of the lesions $(11,12)$. Furthermore, in this two-dimensional analysis, the thickness of the lesion is not taken into account.

The degree of mouse atherosclerosis can also be accurately obtained by the cholesterol quantification mentioned above $(17,19,20)$, which is highly sensitive for the detection of early and advanced atherosclerosis lesions, but misses the identification of the lesion location and complexity, so critical for humans (19) in whom lesions are better measured by cross-sectional aortic histology $(19,24)$. Although extremely laborious, the latter is sensitive enough to distinguish premature from advanced lesions. This situation can be illustrated by LDLR KO and apoE KO mice fed a low-sodium chloride diet (25). After being fed a lowsodium chloride diet for 9 weeks, LDLR KO mice developed premature arterial lipid storage identified by crosssectional aortic histology and that might be missed by the en face examination of the aortic arch (Figure 2). On the other hand, in humans location and complexity of the lesions are critical parameters that determine the severity of the complication, such as thrombosis, plaque rupture, and the organ or tissue affected. Furthermore, LDL me-

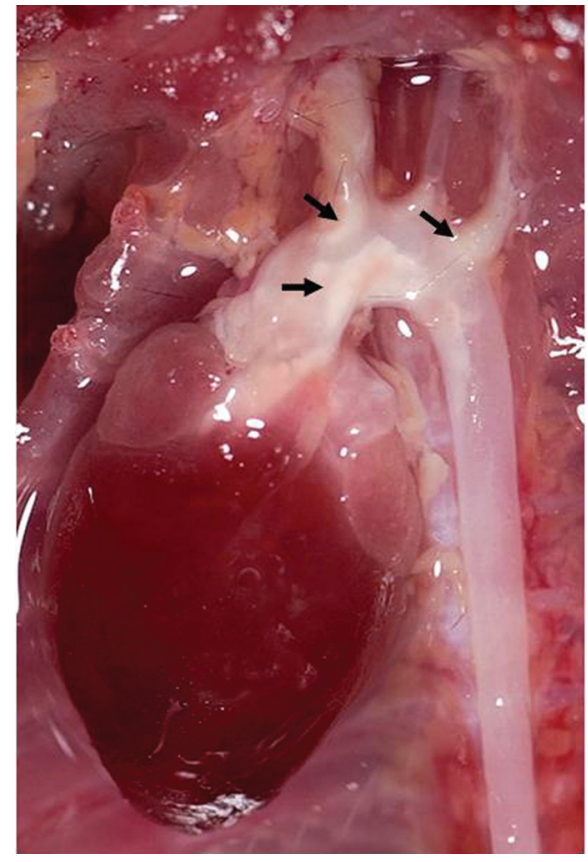

Figure 1. Gross appearance of atherosclerotic lesions indicated by the arrows in an 8-month-old male apolipoprotein $E$ knockout mouse fed a chow diet. Total serum cholesterol was about 450$500 \mathrm{mg} / \mathrm{dL}$.
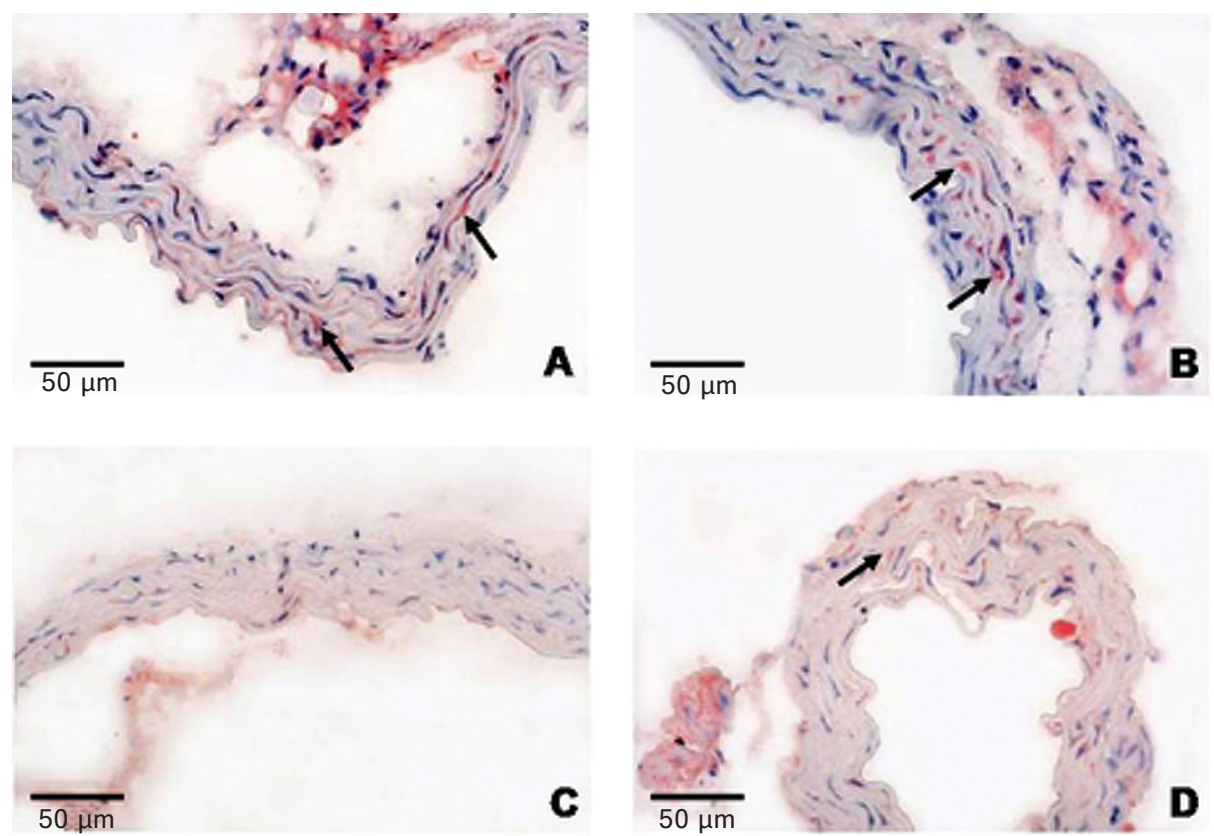

Figure 2. Representative light micrographs of mice cross-sectional arterial aortic arch wall lipid deposit areas (intima and media) stained with oil red-O and counterstained with hematoxylin. Panels $A$ and $B$ : Apolipoprotein $E$ knockout (apoE KO) mice; panels $C$ and $D$ : lipoprotein receptor knockout (LDLR KO) mice. The animals were fed a normal sodium chloride $\operatorname{diet}($ panels $A$ and $C$ ) and a lowsodium chloride diet (panels $B$ and $D$ ) for nine weeks (25). Remarkable aortic fat infiltration is observed in apoE KO mice (A and B) compared to the aortic wall of LDLR KO mice (C and D). Nonetheless, the low-sodium chloride diet increased the arterial fat accumulation in LDLR KO mice but caused no changes in apoE KO mice. These premature lesions, indicated by the arrows, could only be identified by cross-sectional analysis and not by the en face aortic examination. 
tabolism, either in plasma or in cell culture, may be influenced by differences in fatty acid composition of the cholesteryl ester component of the LDL particles $(17,21,26)$. Consequently, although similar arterial cholesteryl ester contents may be found in the experimental groups, the complexity of the atherosclerotic lesion may differ significantly. The opposite may also be true, since it has been shown that simvastatin dramatically reduces the accumulation of cholesterol in the whole aorta in apoE KO mice during a 6-week treatment period; nevertheless, the histological analysis of the aortic root lesions from simvastatintreated and control animals reveals similar lesion morphology. In this case, the effect of simvastatin treatment on the aortic root lesion complexity seems to have little significance when compared to the effect on the cholesteryl ester content in the remainder of the aortic segments (23). In other words, although the cholesterol content of the aortic arch strongly correlates with the degree of atherosclerosis shown by the morphometric technique, the biological and clinical significance obtained by these procedures may markedly differ (19).

Acyl CoA:cholesterol acyltransferase (ACAT) catalyzes the intracellular cholesterol esterification $(27,28)$. Histological analyses of tissues and atherosclerotic lesions have shown that double KO mice for ACAT1 and for apoE, or for LDLR, develop atherosclerotic lesions. However, in addition to the loss of cholesteryl ester, ACAT1 deficiency causes qualitative differences in atherosclerotic lesions and markedly decreases the macrophage content in advanced lesions (29). Thus, chemical measurements of the

\section{References}

1. Dallinga-Thie GM, Schneijderberg VL, van Tol A. Identification and characterization of rat serum lipoprotein subclasses. Isolation by chromatography on agarose columns and sequential immunoprecipitation. J Lipid Res 1986; 27: 1035-1043.

2. Jawien J, Nastalek P, Korbut R. Mouse models of experimental atherosclerosis. J Physiol Pharmacol 2004; 55: 503517.

3. Smith JD, Breslow JL. The emergence of mouse models of atherosclerosis and their relevance to clinical research. $J$ Intern Med 1997; 242: 99-109.

4. Getz GS, Reardon CA. Diet and murine atherosclerosis. Arterioscler Thromb Vasc Biol 2006; 26: 242-249.

5. Daugherty A. Mouse models of atherosclerosis. Am J Med Sci 2002; 323: 3-10.

6. Meir KS, Leitersdorf E. Atherosclerosis in the apolipoprotein-E-deficient mouse: a decade of progress. Arterioscler Thromb Vasc Biol 2004; 24: 1006-1014. esterified cholesterol content would be of little help to define the degree of aortic atherosclerosis and therefore histological analysis would be more appropriate.

Finally, histological analyses deserve criticism because the chemical fixation and inclusion may extract the tissue fat, and also shrink and distort the tissue structures. Thus, this method may be less sensitive for the detection of slight differences among the experimental groups, unless a more suitable procedure based on physical fixation with histological sample freezing using optimal cutting temperature and liquid nitrogen is employed.

Although experimental atherosclerosis can be assessed using advanced imaging techniques such as angiography, Doppler ultrasound, B-mode ultrasound and magnetic resonance (30-32), the main methods employed in the quantification of mouse atherosclerosis are those mentioned in this brief review.

\section{Conclusion}

We conclude that, when measuring experimental atherosclerosis in mice, investigators should be aware of several pitfalls regarding degrees of arterial lesions considered suitable for human pathology. Depending upon the experimental protocols, animal atherosclerosis may vary in intensity, complexity and location. These aspects demand properly sensitive methods of experimental atherosclerosis development and the interpretation and extrapolation of the findings to human pathology demand caution.

7. Breslow JL. Mouse models of atherosclerosis. Science 1996; 272: 685-688.

8. Plump AS, Smith JD, Hayek T, Aalto-Setala K, Walsh A, Verstuyft JG, et al. Severe hypercholesterolemia and atherosclerosis in apolipoprotein E-deficient mice created by homologous recombination in ES cells. Cell 1992; 71: 343353.

9. Ishibashi S, Brown MS, Goldstein JL, Gerard RD, Hammer $\mathrm{RE}$, Herz J. Hypercholesterolemia in low density lipoprotein receptor knockout mice and its reversal by adenovirusmediated gene delivery. J Clin Invest 1993; 92: 883-893.

10. Ishibashi S, Goldstein JL, Brown MS, Herz J, Burns DK. Massive xanthomatosis and atherosclerosis in cholesterolfed low density lipoprotein receptor-negative mice. J Clin Invest 1994; 93: 1885-1893.

11. Ueshima $K$, kihisa-Umeno $H$, Sawada $M$, Nagayoshi $A$, Ozaki T, Takakura S, et al. Possible involvement of enhanced intestinal microsomal triglyceride transfer protein 
(MTP) gene expression in acceleration of lipid absorption by a western-type diet in apolipoprotein $\mathrm{E}$ knockout mice. Life Sci 2004; 76: 179-190.

12. Chi H, Messas E, Levine RA, Graves DT, Amar S. Interleukin-1 receptor signaling mediates atherosclerosis associated with bacterial exposure and/or a high-fat diet in a murine apolipoprotein $\mathrm{E}$ heterozygote model: pharmacotherapeutic implications. Circulation 2004; 110: 1678-1685.

13. Paigen B, Morrow A, Holmes PA, Mitchell D, Williams RA. Quantitative assessment of atherosclerotic lesions in mice. Atherosclerosis 1987; 68: 231-240.

14. Tangirala RK, Rubin EM, Palinski W. Quantitation of atherosclerosis in murine models: correlation between lesions in the aortic origin and in the entire aorta, and differences in the extent of lesions between sexes in LDL receptor-deficient and apolipoprotein E-deficient mice. J Lipid Res 1995; 36: 2320-2328.

15. Palinski W, Ord VA, Plump AS, Breslow JL, Steinberg D, Witztum JL. ApoE-deficient mice are a model of lipoprotein oxidation in atherogenesis. Demonstration of oxidation-specific epitopes in lesions and high titers of autoantibodies to malondialdehyde-lysine in serum. Arterioscler Thromb 1994; 14: 605-616.

16. Miettinen TA, Ahrens EH Jr, Grundy SM. Quantitative isolation and gas-liquid chromatographic analysis of total dietary and fecal neutral steroids. J Lipid Res 1965; 6: 411-424.

17. Rudel LL, Kelley K, Sawyer JK, Shah R, Wilson MD. Dietary monounsaturated fatty acids promote aortic atherosclerosis in LDL receptor-null, human ApoB100-overexpressing transgenic mice. Arterioscler Thromb Vasc Biol 1998; 18: 18181827.

18. Daugherty A, Pure E, Delfel-Butteiger D, Chen S, Leferovich J, Roselaar SE, et al. The effects of total lymphocyte deficiency on the extent of atherosclerosis in apolipoprotein E-/- mice. J Clin Invest 1997; 100: 1575-1580.

19. Choudhury RP, Rong JX, Trogan E, Elmalem VI, Dansky HM, Breslow JL, et al. High-density lipoproteins retard the progression of atherosclerosis and favorably remodel lesions without suppressing indices of inflammation or oxidation. Arterioscler Thromb Vasc Biol 2004; 24: 1904-1909.

20. Adams MR, Golden DL, Register TC, Anthony MS, Hodgin JB, Maeda N, et al. The atheroprotective effect of dietary soy isoflavones in apolipoprotein E-/- mice requires the presence of estrogen receptor-alpha. Arterioscler Thromb Vasc Biol 2002; 22: 1859-1864.

21. Merkel M, Velez-Carrasco W, Hudgins LC, Breslow JL. Compared with saturated fatty acids, dietary monounsaturated fatty acids and carbohydrates increase atherosclerosis and VLDL cholesterol levels in LDL receptor-deficient, but not apolipoprotein E-deficient, mice. Proc Natl Acad Sci U S A 2001; 98: 13294-13299.

22. Nakashima Y, Plump AS, Raines EW, Breslow JL, Ross R. ApoE-deficient mice develop lesions of all phases of atherosclerosis throughout the arterial tree. Arterioscler Thromb 1994; 14: 133-140.

23. Sparrow CP, Burton CA, Hernandez M, Mundt S, Hassing $\mathrm{H}$, Patel S, et al. Simvastatin has anti-inflammatory and antiatherosclerotic activities independent of plasma cholesterol lowering. Arterioscler Thromb Vasc Biol 2001; 21: 115121.

24. Rosenfeld ME, Kauser K, Martin-McNulty B, Polinsky P, Schwartz SM, Rubanyi GM. Estrogen inhibits the initiation of fatty streaks throughout the vasculature but does not inhibit intra-plaque hemorrhage and the progression of established lesions in apolipoprotein E deficient mice. Atherosclerosis 2002; 164: 251-259.

25. Catanozi S, Rocha JC, Passarelli M, Guzzo ML, Alves C, Furukawa LN, et al. Dietary sodium chloride restriction enhances aortic wall lipid storage and raises plasma lipid concentration in LDL receptor knockout mice. J Lipid Res 2003; 44: 727-732.

26. Seo T, Oelkers PM, Giattina MR, Worgall TS, Sturley SL, Deckelbaum RJ. Differential modulation of ACAT1 and ACAT2 transcription and activity by long chain free fatty acids in cultured cells. Biochemistry 2001; 40: 4756-4762.

27. Buhman KF, Accad M, Farese RV. Mammalian acylCoA:cholesterol acyltransferases. Biochim Biophys Acta 2000; 1529: 142-154.

28. Chang TY, Chang CC, Cheng D. Acyl-coenzyme A:cholesterol acyltransferase. Annu Rev Biochem 1997; 66: 613638.

29. Accad M, Smith SJ, Newland DL, Sanan DA, King LE Jr, Linton MF, et al. Massive xanthomatosis and altered composition of atherosclerotic lesions in hyperlipidemic mice lacking acyl CoA:cholesterol acyltransferase 1. J Clin Invest 2000; 105: 711-719.

30. Gan LM, Gronros J, Hagg U, Wikstrom J, Theodoropoulos $\mathrm{C}$, Friberg $\mathrm{P}$, et al. Non-invasive real-time imaging of atherosclerosis in mice using ultrasound biomicroscopy. Atherosclerosis 2007; 190: 313-320.

31. Jaffer FA, Weissleder R. Seeing within: molecular imaging of the cardiovascular system. Circ Res 2004; 94: 433-445.

32. McAteer MA, Schneider JE, Clarke K, Neubauer S, Channon KM, Choudhury RP. Quantification and 3D reconstruction of atherosclerotic plaque components in apolipoprotein E knockout mice using ex vivo high-resolution MRI. Arterioscler Thromb Vasc Biol 2004; 24: 2384-2390. 